\title{
Massive bleeding after plastic stent removal during ERCP: what's next?
}
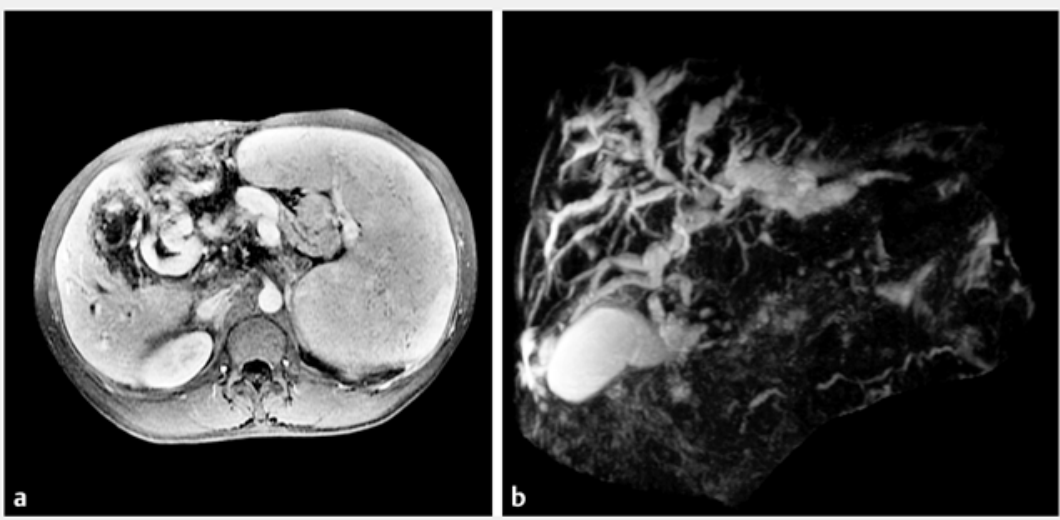

- Fig. 1 Magnetic resonance imaging. a Magnetic resonance portovenography. There is a parallel conglomerate of veins in the porta hepatis formed by paracholedochal collaterals, forming the portal cavernoma. The main portal vein is not seen (thrombosed). b Magnetic resonance cholangiopancreatography. The common bile duct shows luminal irregularity. There is a localized irregular stricture in the common hepatic duct with upstream gross dilatation of the intrahepatic ducts.

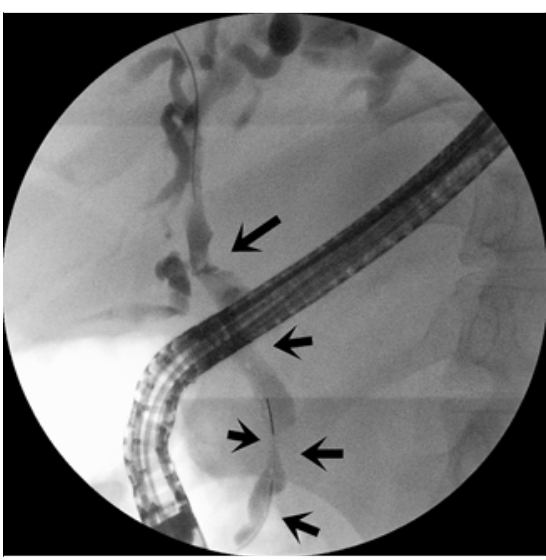

- Fig. 2 Previous endoscopic retrograde cholangiopancreatography showing multiple luminal filling defects (arrows) due to bile duct impressions and indentations, causing wall irregularity.
Portal biliopathy or portal cavernoma cholangiopathy refers to cholangiographic abnormalities, which occur in patients with portal cavernoma. These include shallow bile duct impressions and indentations causing wall irregularity, smooth strictures with upstream dilatation, and luminal filling defects ( Fig. 1, > Fig. 2). These changes occur as a result of pressure on bile ducts from bridging tortuous paracholedochal, epicholedochal, and cholecystic veins [1]. Symptoms of portal cavernoma cholangiopathy include longstanding jaundice due to chronic cholestasis, or biliary pain with or without cholangitis due to biliary stones [2].

We present the case of a 41-year-old man with portal biliopathy secondary to noncirrhotic portal vein thrombosis, who was admitted with obstructive jaundice and cholangitis. He had a biliary plastic stent placed 2 months earlier for obstructive jaundice. The previous stent had become blocked and was removed. A sudden spurt of massive bleeding from the ampulla was noticed. A fully covered self-expandable metal stent (fcSEMS;

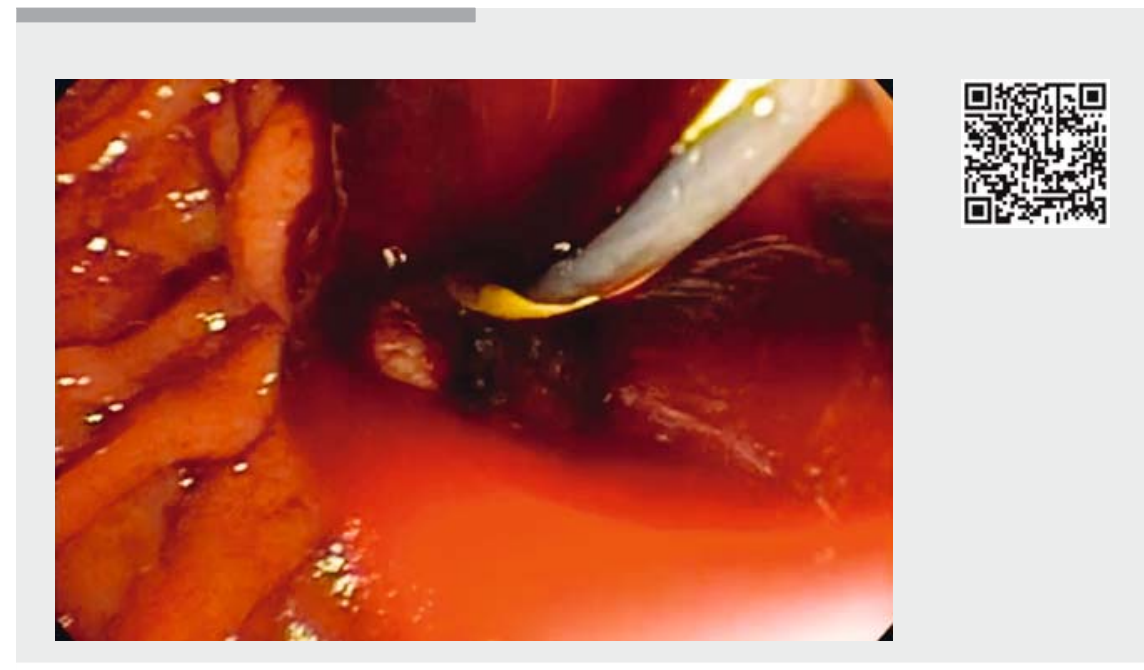

$\checkmark$ Video 1 Two patients with portal biliopathy underwent endoscopic retrograde cholangiopancreatography. Massive bleeding was noticed during the procedure.

Wallflex biliary fcSEMS, $10 \times 60 \mathrm{~mm}$; Boston Scientific, Marlborough, Massachusetts, USA) was deployed, with resolution of the hemorrhage ( $\triangleright$ Video 1 ).

The second case involves endoscopic retrograde cholangiopancreatography (ERCP) in a 54-year-old woman with portal hypertension and cholangitis. Hemobilia was noticed after balloon sweeping. A fcSEMS was used with success ( $>$ Video $\mathbf{1}$ ).

ERCP with plastic stent exchanges is the first-line intervention for jaundice or cholangitis due to biliary strictures. If 
biliary obstruction does not resolve, portosystemic shunt surgery or transjugular intrahepatic portosystemic stent shunt is performed to decompress the portal cavernoma. Rarely, plastic stents may also induce bleeding due to rupture of the hepatic artery, which can be managed with angiography with coiling of the artery $[3,4]$. In general, placement of metal stents is not recommended in patients with benign diseases who are expected to have prolonged survival. Even the short-term use of removable metal stents may be fraught with problems and should be considered with care. However, deployment of a fcSEMS appears to be a useful maneuver to control massive hemobilia [5].

Endoscopy_UCTN_Code_CPL_1AK_2AC

\section{Competing interests}

None

The Authors

Marcos Eduardo Lera, Mauricio Kazuyoshi Minata, Ralph Braga Duarte, Sergio Eiji Matuguma, Paulo Sakai, Wellington Andraus, Eduardo Guimarães Hourneaux de Moura Gastroenterology Department, University of São Paulo, São Paulo, Brazil
Corresponding author

\section{Mauricio Kazuyoshi Minata, MD}

Gastrointestinal Endoscopy Unit Gastroenterology Department, University of São Paulo, Avenida Dr. Enéas de Carvalho Aguiar, n' $155,6^{\circ}$ andar, São Paulo, SP 05403-900, Brazil Fax: +55-11-26610000

mauriciominata@hotmail.com

\section{References}

[1] Khuroo MS, Rather AA, Khuroo NS et al. Portal biliopathy. World J Gastroenterol 2016; 22: $7973-7982$

[2] Dhiman RK, Saraswat VA, Valla DC et al. Portal cavernoma cholangiopathy: consensus statement of a working party of the Indian national association for study of the liver. J Clin Exp Hepatol 2014; 4: S2-S14

[3] Chun JM, Ha HT, Choi YY et al. Intrahepatic artery pseudoaneurysm-induced hemobilia caused by a plastic biliary stent after ABOincompatible living-donor liver transplantation: a case report. Transplant Proc 2016; 48: $3178-3180$

[4] Lee SH, Hong SG, Lee KY et al. Delayed severe hemobilia after endoscopic biliary plastic stent insertion. Clin Endosc 2016; 49: $303-307$

[5] D’Assuncao MA, Velázquez-Aviña J, Council L et al. Biliary cast syndrome in portal hypertensive biliopathy: direct cholangioscopic findings and endoscopic therapy with metal stent. Endosc Int Open 2015; 3: E223 -E225

\section{Bibliography}

DOI https://doi.org/10.1055/s-0043-119350

Published online: 25.9.2017

Endoscopy 2017; 49: E303-E304

(c) Georg Thieme Verlag KG

Stuttgart · New York

ISSN 0013-726X

\section{ENDOSCOPY E-VIDEOS}

https:/|eref.thieme.de/e-videos

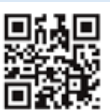

Endoscopy E-Videos is a free access online section, reporting on interesting cases and new

techniques in gastroenterological endoscopy. All papers include a high quality video and all contributions are freely accessible online.

This section has its own submission website at https://mc.manuscriptcentral.com/e-videos 